\title{
A practical $\log M A R$ near reference table for low vision practitioners: Design and applications
}

\author{
Alabi O Oduntan*
}

\author{
Department of Optometry, School of Health Sciences, University of Limpopo, Turfloop Campus, \\ Private Bag x1106, Sovenga, 0727 South Africa \\ <alabio@ul.ac.za>
}

\begin{abstract}
LogMAR charts are particularly useful for visual acuity (VA) measurement for low vision patients as they simplify conversion of nonstandard viewing distance visual acuities to standard values. Also, the process of predicting various quantities involved in the prescription of optical devices for patients are greatly facilitated. However, the processes involved in the use of this $\log$ MAR principle require series of multiplication and division by the logMAR ratio of 1.2589 . A table computed and presented in this article provides easy reference for the conversions and predictions needed for the various quantities at near. The table (Table 1) is computed using the $\log$ MAR scale of 1.2589 in $\log \mathrm{MAR}, \mathrm{M}$ and $\mathrm{N}$ notations. The table contains VA values between logMAR 1.4 (10M or 80 point) and $\log$ MAR 0.18 (1.3M or10 point) in steps of 1.2589 for reduced (non-standard) viewing distances ranging from $31.8 \mathrm{~cm}(0.32$ $\mathrm{m})$ to $3.2 \mathrm{~cm}(0.03 \mathrm{M})$. The table contains values which can be used to convert visual acuity values measured at reduced near viewing distances to standard visual acuity values. The values also can be used to represent any of the quantities involved in the prescription of optical devices for low vision patients. The use of the table for converting reduced distance
\end{abstract}

VA values to standard values and for predicting optical powers and visual performance of low vision patients are discussed with relevant examples. Like all principles based on the logMAR principles, the table is quite versatile in VA conversion and prediction of the various quantities such as print size that can be read by the low vision patient when factors such as viewing distance or power are varied.

Keywords: Conversion table, logMAR, near visual acuity, low vision, magnifiers, print sizes.

\section{Introduction}

A common presenting goal of low vision patients is to be able to perform near tasks such as reading ${ }^{1,2}$. Distance and near visual acuity values have been recommended for calculating magnifying powers needed by low vision patients for near tasks ${ }^{3-6}$ and are still being used by many clinicians. The use of conventional acuity, especially the distance values has, however, been criticized for not being ideal for reading power calculation ${ }^{7,8}$. Patients with low vision do not show a close relationship between the threshold visual angle for isolated capital letters and for continuous text, therefore conventional tests of acuity are of little use in predicting the magnification that the patient

*BSc (Hons) Optom PhD

Received 20 June 2006; revised version accepted 9 December 2006 
needs to read with reasonable speed and accuracy $^{7}$. Also, printed material presents a more complex and difficult task than does acuity letters; there is often poor agreement between reading acuity and distance letter acuity and these discrepancies become most pronounced when there is a disturbance of macular function as in macular degeneration and amblyopia ${ }^{8}$.

Although, Snellen acuity charts are still being used by many clinicians worldwide for examination of both normally and visually impaired patients, the use of $\log$ MAR charts are preferable. The advantages of these charts over the Snellen ones for routing clinical and research work have been discussed by several authors ${ }^{9-14}$. The use of $\log$ MAR acuity, word reading or continuous sentences offer greater advantages for examination and prescription of optical devices for low vision patients.

For calculation of magnification power for near tasks, there are several methods that are being used. One of these is the ratio of the print size that the patient can read and the estimated print size that he or she would like to read. For example, if a patient can read print of $5 \mathrm{M}$ at a specific distance; to read print of $2.5 \mathrm{M}$ at the same distance will require magnification of $5 / 2.5=2 \mathrm{x}$. Another method is the use of $1 \mathrm{M}$ as a direct measure of required dioptric power of the reading magnifier? ${ }^{7}$. If a patient is able

Table 1. The applications and advantages of the table

\begin{tabular}{|c|c|c|c|c|c|c|c|c|c|c|c|}
\hline $\begin{array}{l}\mathrm{SVD} / \\
\mathrm{VA}\end{array}$ & \multicolumn{11}{|c|}{$\begin{array}{l}\text { NON-STANDARD VIEWING DISTANCES (LogMAR / M / N) } \\
\text { ADJUSTED VISUAL ACUITY (LogMAR / M / N) }\end{array}$} \\
\hline $\begin{array}{l}40 \mathrm{~cm} \\
0.4 \mathrm{M}\end{array}$ & $\begin{array}{l}32 \\
0.32\end{array}$ & $\begin{array}{l}25 \\
0.25\end{array}$ & $\begin{array}{l}20.0 \\
0.20\end{array}$ & $\begin{array}{l}16.0 \\
0.16\end{array}$ & $\begin{array}{l}12.7 \\
0.13\end{array}$ & $\begin{array}{l}10.0 \\
0.10\end{array}$ & $\begin{array}{l}8.0 \\
0.08\end{array}$ & $\begin{array}{l}6.3 \\
0.06\end{array}$ & $\begin{array}{l}5.0 \\
0.06\end{array}$ & $\begin{array}{l}4.0 \\
0.04\end{array}$ & $\begin{array}{l}3.2 \\
0.03\end{array}$ \\
\hline $\begin{array}{l}1.4 \\
10 \\
80\end{array}$ & $\begin{array}{l}1.11 \\
8 \\
64\end{array}$ & $\begin{array}{l}0.9 \\
6.3 \\
51\end{array}$ & $\begin{array}{l}0.7 \\
5 \\
40\end{array}$ & $\begin{array}{l}0.6 \\
4 \\
32\end{array}$ & $\begin{array}{l}0.44 \\
3.2 \\
25\end{array}$ & $\begin{array}{l}0.35 \\
2.5 \\
20\end{array}$ & $\begin{array}{l}0.3 \\
2 \\
16\end{array}$ & $\begin{array}{l}0.22 \\
1.6 \\
13\end{array}$ & $\begin{array}{l}0.18 \\
1.3 \\
10\end{array}$ & $\begin{array}{l}0.14 \\
1 \\
8\end{array}$ & $\begin{array}{l}0.11 \\
0.8 \\
6\end{array}$ \\
\hline $\begin{array}{l}1.1 \\
8 \\
64 \\
\end{array}$ & $\begin{array}{l}0.9 \\
6.3 \\
51 \\
\end{array}$ & $\begin{array}{l}0.7 \\
5 \\
40 \\
\end{array}$ & $\begin{array}{l}0.6 \\
4 \\
32 \\
\end{array}$ & $\begin{array}{l}0.44 \\
3.2 \\
25 \\
\end{array}$ & $\begin{array}{l}0.35 \\
2.5 \\
20 \\
\end{array}$ & $\begin{array}{l}0.3 \\
2 \\
16 \\
\end{array}$ & $\begin{array}{l}0.22 \\
1.6 \\
13 \\
\end{array}$ & $\begin{array}{l}0.18 \\
1.3 \\
10 \\
\end{array}$ & $\begin{array}{l}0.14 \\
1 \\
8 \\
\end{array}$ & $\begin{array}{l}0.11 \\
0.8 \\
6 \\
\end{array}$ & $\begin{array}{l}0.1 \\
0.64 \\
5 \\
\end{array}$ \\
\hline $\begin{array}{l}0.9 \\
6.3 \\
51\end{array}$ & $\begin{array}{l}0.7 \\
5 \\
40\end{array}$ & $\begin{array}{l}0.6 \\
4 \\
32\end{array}$ & $\begin{array}{l}0.44 \\
3.2 \\
25\end{array}$ & $\begin{array}{l}0.35 \\
2.5 \\
20\end{array}$ & $\begin{array}{l}0.3 \\
2 \\
16\end{array}$ & $\begin{array}{l}0.22 \\
1.6 \\
13\end{array}$ & $\begin{array}{l}0.18 \\
1.3 \\
10\end{array}$ & $\begin{array}{l}0.14 \\
1 \\
8\end{array}$ & $\begin{array}{l}0.11 \\
0.8 \\
6\end{array}$ & $\begin{array}{l}0.1 \\
0.64 \\
5\end{array}$ & $\begin{array}{l}0.07 \\
0.52 \\
4\end{array}$ \\
\hline $\begin{array}{l}0.7 \\
5 \\
40 \\
\end{array}$ & $\begin{array}{l}0.6 \\
4 \\
32 \\
\end{array}$ & $\begin{array}{l}0.44 \\
3.2 \\
25 \\
\end{array}$ & $\begin{array}{l}0.35 \\
2.5 \\
20 \\
\end{array}$ & $\begin{array}{l}0.3 \\
2 \\
16 \\
\end{array}$ & $\begin{array}{l}0.22 \\
1.6 \\
13 \\
\end{array}$ & $\begin{array}{l}0.18 \\
1.3 \\
10 \\
\end{array}$ & $\begin{array}{l}0.14 \\
1 \\
8 \\
\end{array}$ & $\begin{array}{l}0.11 \\
0.8 \\
6 \\
\end{array}$ & $\begin{array}{l}0.1 \\
0.64 \\
5 \\
\end{array}$ & $\begin{array}{l}0.07 \\
0.52 \\
4 \\
\end{array}$ & $\begin{array}{l}0.06 \\
4 \\
32 \\
\end{array}$ \\
\hline $\begin{array}{l}0.6 \\
4 \\
32 \\
\end{array}$ & $\begin{array}{l}0.44 \\
3.2 \\
25 \\
\end{array}$ & $\begin{array}{l}0.35 \\
2.5 \\
20 \\
\end{array}$ & $\begin{array}{l}0.3 \\
2 \\
16 \\
\end{array}$ & $\begin{array}{l}0.22 \\
1.6 \\
13 \\
\end{array}$ & $\begin{array}{l}0.18 \\
1.3 \\
10 \\
\end{array}$ & $\begin{array}{l}0.14 \\
1 \\
8 \\
\end{array}$ & $\begin{array}{l}0.11 \\
0.8 \\
6 \\
\end{array}$ & $\begin{array}{l}0.1 \\
0.64 \\
5 \\
\end{array}$ & $\begin{array}{l}0.07 \\
0.52 \\
4 \\
\end{array}$ & $\begin{array}{l}0.06 \\
4 \\
32 \\
\end{array}$ & $\begin{array}{l}0.05 \\
0.32 \\
2.5 \\
\end{array}$ \\
\hline $\begin{array}{l}0.44 \\
3.2 \\
25 \\
\end{array}$ & $\begin{array}{l}0.35 \\
2.5 \\
20 \\
\end{array}$ & $\begin{array}{l}0.3 \\
2 \\
16 \\
\end{array}$ & $\begin{array}{l}0.22 \\
1.6 \\
13 \\
\end{array}$ & $\begin{array}{l}0.18 \\
1.3 \\
10 \\
\end{array}$ & $\begin{array}{l}0.14 \\
1 \\
8 \\
\end{array}$ & $\begin{array}{l}0.11 \\
0.8 \\
6 \\
\end{array}$ & $\begin{array}{l}0.1 \\
0.64 \\
5 \\
\end{array}$ & $\begin{array}{l}0.07 \\
0.52 \\
4 \\
\end{array}$ & $\begin{array}{l}0.06 \\
4 \\
32 \\
\end{array}$ & $\begin{array}{l}0.05 \\
0.32 \\
2.5 \\
\end{array}$ & $\begin{array}{l}0.04 \\
0.26 \\
2 \\
\end{array}$ \\
\hline $\begin{array}{l}0.35 \\
2.5 \\
20 \\
\end{array}$ & $\begin{array}{l}0.3 \\
2 \\
16 \\
\end{array}$ & $\begin{array}{l}0.22 \\
1.6 \\
13 \\
\end{array}$ & $\begin{array}{l}0.18 \\
1.3 \\
10 \\
\end{array}$ & $\begin{array}{l}0.14 \\
1 \\
8 \\
\end{array}$ & $\begin{array}{l}0.11 \\
0.8 \\
6 \\
\end{array}$ & $\begin{array}{l}0.1 \\
0.64 \\
5 \\
\end{array}$ & $\begin{array}{l}0.07 \\
0.52 \\
4 \\
\end{array}$ & $\begin{array}{l}0.06 \\
4 \\
32 \\
\end{array}$ & $\begin{array}{l}0.05 \\
0.32 \\
2.5 \\
\end{array}$ & $\begin{array}{l}0.04 \\
0.26 \\
2 \\
\end{array}$ & $\begin{array}{l}0.03 \\
0.20 \\
1.6 \\
\end{array}$ \\
\hline $\begin{array}{l}0.3 \\
2 \\
16 \\
\end{array}$ & $\begin{array}{l}0.22 \\
1.6 \\
13 \\
\end{array}$ & $\begin{array}{l}0.18 \\
1.3 \\
10 \\
\end{array}$ & $\begin{array}{l}0.14 \\
1 \\
8 \\
\end{array}$ & $\begin{array}{l}0.11 \\
0.8 \\
6 \\
\end{array}$ & $\begin{array}{l}0.1 \\
0.64 \\
5 \\
\end{array}$ & $\begin{array}{l}0.07 \\
0.52 \\
4 \\
\end{array}$ & $\begin{array}{l}0.06 \\
4 \\
32 \\
\end{array}$ & $\begin{array}{l}0.05 \\
0.32 \\
2.5 \\
\end{array}$ & $\begin{array}{l}0.04 \\
0.26 \\
2 \\
\end{array}$ & $\begin{array}{l}0.03 \\
0.20 \\
1.6 \\
\end{array}$ & $\begin{array}{l}0.02 \\
0.16 \\
1.3 \\
\end{array}$ \\
\hline $\begin{array}{l}0.2 \\
1.6 \\
13 \\
\end{array}$ & $\begin{array}{l}0.18 \\
1.3 \\
10 \\
\end{array}$ & $\begin{array}{l}0.14 \\
1 \\
8 \\
\end{array}$ & $\begin{array}{l}0.11 \\
0.8 \\
6 \\
\end{array}$ & $\begin{array}{l}0.1 \\
0.64 \\
5 \\
\end{array}$ & $\begin{array}{l}0.07 \\
0.52 \\
4 \\
\end{array}$ & $\begin{array}{l}0.06 \\
4 \\
32 \\
\end{array}$ & $\begin{array}{l}0.05 \\
0.32 \\
2.5 \\
\end{array}$ & $\begin{array}{l}0.04 \\
0.26 \\
2 \\
\end{array}$ & $\begin{array}{l}0.03 \\
0.20 \\
1.6 \\
\end{array}$ & $\begin{array}{l}0.02 \\
0.16 \\
1.3 \\
\end{array}$ & $\begin{array}{l}0.0016 \\
0.13 \\
1\end{array}$ \\
\hline $\begin{array}{l}0.18 \\
1.3 \\
10\end{array}$ & $\begin{array}{l}0.14 \\
1 \\
8 \\
\end{array}$ & $\begin{array}{l}0.11 \\
0.8 \\
6 \\
\end{array}$ & $\begin{array}{l}0.1 \\
0.64 \\
5\end{array}$ & $\begin{array}{l}0.07 \\
0.52 \\
4\end{array}$ & $\begin{array}{l}0.06 \\
4 \\
32 \\
\end{array}$ & $\begin{array}{l}0.05 \\
0.32 \\
2.5\end{array}$ & $\begin{array}{l}0.04 \\
0.26 \\
2 \\
\end{array}$ & $\begin{array}{l}0.03 \\
0.20 \\
1.6\end{array}$ & $\begin{array}{l}0.02 \\
0.16 \\
1.3\end{array}$ & $\begin{array}{l}0.0016 \\
0.13 \\
1\end{array}$ & $\begin{array}{l}0.012 \\
0.10 \\
0.8\end{array}$ \\
\hline
\end{tabular}


to read certain $\mathrm{M}$ units at $40 \mathrm{~cm}$, the reading ability in $\mathrm{M}$ units times $2.5 \mathrm{D}$ is equal to the power of the required magnifier. For example, if a patient can read $6 \mathrm{M}$ at $40 \mathrm{~cm}$ and he or she wishes to read $1 \mathrm{M}$, the power required will be $2.5 \times 6=+15.00 \mathrm{D}$. Although these and other methods are still in use today, the use of the logMAR principle greatly facilitates the process of evaluation and prescription of devices for low vision patients as described below.

During the examination of a low vision patient, it is often necessary to reduce the viewing distance to enable the patient to read a particular print size or to read smaller print size on the chart. In this situation, the print meant to be read at the standard near viewing distance of $40 \mathrm{~cm}$ may be presented to the patient at a reduced distance such as $16 \mathrm{~cm}$. Subsequently, the VA value may need to be converted to standard viewing distance $(40 \mathrm{~cm})$ value. If a $\log$ MAR chart is used for the VA measurement, the conversion is quite simple, provided that appropriate reduction in viewing distance in steps of 1.2589 is employed. The ease of conversion of the non-standard VA values to standard value is an important feature of the $\log$ MAR principle. The process, however, involves series of multiplication and division of viewing distances by $\log$ MAR ratio of 1.2589 . The process can, however, be made easy by the use of a conversion table. A conversion table for distance VA has been computed and described in a previous article ${ }^{14}$. In this article, the computation of a near conversion table (Table 1) and its applications are described.

\section{Method}

The table was computed using the logMAR scale of 1.2589 in $\log$ MAR, $\mathrm{M}$ and $\mathrm{N}$ notations. The table contains VA values between logMAR $1.4(10 \mathrm{M}$ or $\mathrm{N} 80)$ and $\log \mathrm{MAR} 0.18(1.3 \mathrm{M}$ or N10) in steps of 1.2589 for reduced (non-standard) viewing distances ranging from $31.8 \mathrm{~cm}$ $(0.32 \mathrm{~m})$ to $3.2 \mathrm{~cm}(0.03 \mathrm{~m})$. The VA values corresponding to the VA at reduced distances were calculated and presented in the table. The various values shown in the table can be used appropriately to represent other quantities such as power, viewing distance, magnification et cetera in the various calculations for low vision patients. The actual table will be produced in an A3 size for easy reference.

\section{The applications and advantages of the table}

One of the uses of the table is to convert nonstandard viewing distance to standard value. The following examples will illustrate the uses and advantages of the table in this regard:

Example 1: A patient reads $0.7 \log$ MAR $(5 \mathrm{M}$ or N40) at a reduced distance of $20 \mathrm{~cm}$. What is the equivalent value of this $\mathrm{VA}$ at the standard viewing distance of $40 \mathrm{~cm}$ ? By dividing $40 \mathrm{~cm}$ by 1.2589 three times, we would arrive at 20 $\mathrm{cm}$. This shows that the viewing distance has been reduced by a factor of $3 \log$ MAR steps. Therefore, the VA at standard viewing distance will be three $\log$ MAR steps larger print. This can be calculated by multiplying 0.7 logMAR ( $5 \mathrm{M}$ or N40) three times by 1.2589 . The VA will then be $\log$ MAR 1.4 (10M or N80). The use of the table helps to avoid these divisions and multiplications. Referring to the table, it can be seen that $20 \mathrm{~cm}$ is 3 steps from $40 \mathrm{~cm}$ (row 1). The practitioner can therefore, simply move three steps from $0.7 \log$ MAR ( $5 \mathrm{M}$ or 40 point) to logMAR 1.4 (10M or N80) on the standard viewing distance column 1.

Conversely, if a patient can read logMAR 1.4 $(10 \mathrm{M}$ or $\mathrm{N} 80)$ at $40 \mathrm{~cm}$, what will he be able to read if the viewing distance is reduced to 20 $\mathrm{cm}$ ? The examiner needs to calculate how many steps that the viewing distance has been reduced in order to predict how many steps the patient will read down the chart. Calculation will reveal three $\log$ MAR steps in viewing distance reduction. Therefore, the patient will be expected to read three $\log$ MAR steps down the chart. This will need to be calculated by dividing $\log$ MAR 1.4 (10M or N80) three times which leads to logMAR 0.7 (5M or N40). Using the table, $40 \mathrm{~cm}$ (row 1) to $20 \mathrm{~cm}$ (row 4) is three logMAR steps, therefore, moving three steps down column 1 
from logMAR 1.4 (10M or N80) will lead to $0.7 \log$ MAR ( $5 \mathrm{M}$ or 40 point), which is the VA that the patient will be expected to read at 20 $\mathrm{cm}$. The multiplication and division processes involved are even more demanding if the difference between the standard viewing distance and reduced viewing distance is high as shown in example 2.

Example 2: A patient can read logMAR 0.1 $(0.64 \mathrm{M}$ or $\mathrm{N} 5)$ at $5 \mathrm{~cm}$. What is the equivalent value of his or her visual acuity at the standard viewing distance of $40 \mathrm{~cm}$ ? By calculation, dividing $40 \mathrm{~cm}$ by 1.2589 nine times will lead to $5 \mathrm{~cm}$. This implies that the reduction in viewing distance is $9 \log$ MAR steps. The equivalent VA value will be nine logMAR steps larger prints on the chart. This will be calculated by multiplying $\log$ MAR $0.1(0.64 \mathrm{M}$ or N5) by 1.2589 nine times, a process that will lead to logMAR 0.7 (5M or N40). The use of the table presented here greatly simplifies this process. The clinician simply needs to locate $5 \mathrm{~cm}$ in row 1 , column 10 , then identify $\log$ MAR 0.1 $(0.64 \mathrm{M}$ or $\mathrm{N} 5)$ in that column on row 5 . He or she can then read the corresponding value on column 1 , row 5 , which in this case is $\log$ MAR 0.7 (5M or N40) Conversely, if a patient can read $\log$ MAR $0.7(5 \mathrm{M})$ and $\mathrm{N} 40$ at $40 \mathrm{~cm}$; what will he or she be expected to read at $5 \mathrm{~cm}$ ?. The clinician simply needs to identify logMAR 0.7 ( $5 \mathrm{M}$ or $\mathrm{N} 40$ ) on column 1 , row 5 , and follow the row to $\operatorname{logMAR} 0.1(0.64 \mathrm{M}$ or N5) in column 10 where $5 \mathrm{~cm}$ is located, which is quite easy and faster than the calculation method.

Another important feature of the $\log$ MAR near charts in relation to low vision care is that the quantities involved in the optical prescriptions for near vision are proportional to one another. The angular subtense of a print is inversely proportional to the viewing distance and the dioptric power of the near addition is inversely proportional to the focal distance of the lens. Also, the magnification provided by a device is directly proportional the dioptric power and the threshold print size is inversely proportional to the magnification used or directly proportional to the viewing distance and so on ${ }^{15}$. Because of these features, the logMAR reading charts can be used to predict optical needs and performance of a patient with an optical device of known power. The use of the table presented in this article facilitates these various conversions. The following examples illustrate the use and advantages of the conversion / prediction table.

Powers and focal lengths of magnifiers are particularly important in low vision care because magnifying lenses are high power plus lenses. Consequently, their foci are very important because, if the patient does not look through these, clear vision will not be possible. The use of this reference table in low vision care to predict focal lengths or viewing distances for devices such as spectacle magnifiers can be explained as follows:

Example 3: A patient, who previously used a magnifier of $+8.00 \mathrm{D}$, has the power of his prescription increased to $+20.00 \mathrm{D}$ due to increase in visual demand. What will be the viewing distance for the new device? Calculation will show that the change in power is four logMAR steps. Therefore, the viewing distance will reduce by four logMAR steps. Calculation will therefore show viewing distance change from 12.5 to 5 $\mathrm{cm}$. From the table (row 1 can be used), from 8.0 to 20 (representing powers) is four steps upward shift in the $\log$ MAR scale. The focal length (viewing distance) will also change (reduce) by four logMAR step from $12.5 \mathrm{~cm}$ (for $+8.00 \mathrm{D}$ ) to $5 \mathrm{~cm}$ (row 1 column 10 on the Table 1) for the new power. This implies that, if the dioptric power of the magnifier required by the patient is increased by a certain $\log$ MAR ratio, the viewing distance (focal distance of the lens) will need to be reduced by the same ratio for the patient to see the print in focus. The various calculations involved can be bypassed by using the table.

Direct proportionality of the magnification with dioptric power is important in low vision care because, as power is increased, it may be necessary to know the magnification that will be 
provided for the patient. The use of the table in this case can be explained by the following example:

Example 4: A patient has a magnifier which provided magnification of $2 x$; if it is anticipated that, due to change in visual need, the patient will now benefit from a magnification of $4 x$. Without calculation, power needed can be read from the table as follows. The magnification has increased by three $\log$ MAR steps; therefore the power of the device will need to increase by the same factor. Calculation will show that the power will change $+8.00 \mathrm{D}$ to $+16.00 \mathrm{D}$. Using the table (row one) shows that three logMAR steps from 8 will lead to 16 which is what calculations will reveal. Therefore, if the ratio of increase or decrease in magnification required is known, the dioptric power needed will just be an increase in ratio of the original dioptric power and can be read directly from the table.

The table can also be used to predict the print size that a patient is expected to read when the dioptric power of the magnifier is known or changes.

Example 5: Suppose a patient can read logMAR 0.6 (4M or N32) at $40 \mathrm{~cm}$ with a magnifier of power $+5.00 \mathrm{D}$. If the clinician decides to increase the power to $+8.00 \mathrm{D}$, what print size is the patient expected to read? The change in power is 2 steps increase on the logMAR scale (row 1). The patient will therefore, be expected to read 2 steps down the logMAR chart (column 1 of the table), which calculation will show to be $0.35 \log$ MAR $(2.5 \mathrm{M}$ or N20). These can be read directly on the table. Two steps (column one) from $\log$ MAR $0.6(4 \mathrm{M}$ or N32) will lead to $0.35 \log$ MAR (2.5M or N20). Similarly, the power of magnifier needed by a patient to read a particular print can be calculated easily by moving in appropriate steps on the logMAR scale of the table if the change in print size is known.

The direct proportionality of print size and viewing distance using the logMAR chart and the table can be explained as follows: As the viewing distance is reduced, the angular sub- tense of the print increases correspondingly (relative distance magnification), therefore the patient will be expected to read smaller print size which corresponds to the number of logMAR steps by which the viewing distance has been reduced as shown in the following example:

Example 6: A patient can read 6.3M (0.9 logMAR or N51) at $25 \mathrm{~cm}$. If it is anticipated that the patient will achieve her visual goal if she is able to read $2 \mathrm{M}(0.3 \log \mathrm{MAR}$ or N16) print size at the same distance. Using the principle of relative distance magnification, what reduction in viewing distance will make this possible? By calculation, the reduction in the print size is $5 \log$ MAR steps. Decreasing the viewing distance by a factor of $5 \log$ MAR steps by calculation from $25 \mathrm{~cm}$ will lead to $8 \mathrm{~cm}$ (row 1 of the table). This will afford the visual resolution needed by the patient to read the print. The clinician using the table simply has to count how many steps from $6.3 \mathrm{M}$ (0.9 logMAR or N51) (from anywhere in the table e.g. second row) will lead him or her to $2 \mathrm{M}(0.3 \log$ MAR or N16). This will be five steps. He or she can then reduce the viewing distance by the same ratio from $25 \mathrm{~cm}$ to $8 \mathrm{~cm}$, which is the required viewing distance.

Example 7: If a patient can read 1.4 logMAR (10M or N80) at $40 \mathrm{~cm}$ and the viewing distance is reduced to $20 \mathrm{~cm}$; what print size is the patient expected to read? By calculation, the reduction in viewing distance represents 3 $\log$ MAR steps. The patient will therefore be expected to read 3 steps on the smaller prints on the chart, which will be $0.7 \log$ MAR $(5 \mathrm{M})$ (N40) by calculation. Using the table, from 40 to 20 is three $\log$ MAR steps (row 1). A three step on the first column of the table from 1.4 $\log$ MAR $(10 \mathrm{M}$ or N80) will lead to 0.7 logMAR (5M or N40). The table can therefore be used easily to predict the change in print size to be read when the viewing distance in reduced by certain $\log$ MAR ratio steps. 


\section{Conclusion}

Because of the various predictions afforded by the $\log$ MAR principle, the use of $\log$ MAR near chart can be used to estimate the print size that a patient would resolve if the working distance or dioptric power of the device was changed appropriately ${ }^{15}$. The table described in this article affords easy reference for all the calculations that the low vision practitioner may wish to do regarding conversion of nonstandard viewing distance visual acuities to standard values and predicting quantities resulting from changes such as viewing distance, print sizes, dioptric powers et cetera during low vision patient assessment and in the prescription of magnifying powers. The table is versatile as it can be applied to various quantities such as powers (diopters), focal lengths, magnification, print sizes ( $\mathrm{mm}, \mathrm{cm}$, and inches), changes in viewing distances, changes in angular size et cetera. Also, the rows and columns can be used interchangeably where relevant values are available.

\section{References}

1. Lovie-Kitchin JE, Whittaker SG. Prescribing near magnification for low vision patients. Clin Exp Optom 1999 82 214-224.

2. Stelmack JA, Rosenbloom AA, Brenneman CS, Stelmack TR. Patient's perception of need of low vision devices. $J$ Vis Imp Blind 200397 521-516.

3. Kestenbaum A, Sturman RM. Reading glasses for patients with very poor vision. Arch Ophthalmol 1956 56 451-470.

4. Mehr EB, Freid AN. Low vision care. Chicago: Professional Press incorporated, 1975.

5. Fonda G. Management of low vision. New York: Thiemestratton, 1981.

6. Faye EE. Clinical low vision. 2nd ed. Boston: Little, Brown and Co, 1985.

7. Sloan LL, Brown DJ. Reading cards for selection of optical aids for the partially sighted. Am J Ophthalmol 1963 55 1187-1199.

8. Bailey IL, Lovie JE. The design and use of new near vision chart. Am J Optom Physiol Opt 198057 378-387.

9. Bailey IL, Lovie JE. New design principles for visual acuity letter charts. Am J Optom Physiol Opt $1976 \mathbf{5 3}$ 740-745.

10. Westheimer G. Scaling visual acuity measurements. Arch Ophthalmol 197997 327-330.

11. Ferris FL, Kassof A. Bresnick G and Bailey I. New visual acuity chart for clinical research. Am J Ophthalmol 198294 91-96.
12. Strong G, Woo G. A distance visual acuity chart incorporating some new design features. Arch Ophthalmol 1985 103 44-46.

13. Johnston AW. Making sense of $\mathrm{M}, \mathrm{N}$ and $\log \mathrm{MAR}$ systems of specifying visual acuity. Problems in Optom 19913 394-407.

14. Oduntan AO. Visual acuity measurement for statistical analysis and graphical representation $S$ Afr Optom 2001 60 97-101.

15. Bailey IL. Prescribing low vision reading aids - A new approach. Optom Monthly 1981. 